\title{
Exploring diffusion and sorption processes at the Mont Terri rock laboratory (Switzerland): lessons learned from 20 years of field research
}

\author{
Olivier X. Leupin ${ }^{1}$ Luc R. Van Loon ${ }^{2}$ Thomas Gimmi ${ }^{2,3} \cdot$ Paul Wersin ${ }^{3}$. \\ Josep M. Soler ${ }^{4,5}$
}

Received: 19 April 2016/Accepted: 17 December 2016/Published online: 7 March 2017

(c) The Author(s) 2017. This article is published with open access at Springerlink.com

\begin{abstract}
Transport and retardation parameters of radionuclides, which are needed to perform a safety analysis for a deep geological repository for radioactive waste in a compacted claystone such as Opalinus Clay, must be based on a detailed understanding of the mobility of nuclides at different spatial scales (laboratory, field, geological unit). Thanks to steadily improving experimental designs, similar tracer compositions in different experiments and complementary small laboratory-scale diffusion tests, a unique and large database could be compiled. This paper presents the main findings of 20 years of diffusion and retention experiments at the Mont Terri rock laboratory and their impact on safety analysis.
\end{abstract}

Keywords Nuclide transport · Sorption · Porosity $\cdot$ Porous media $\cdot$ Claystone $\cdot$ Opalinus Clay $\cdot$ Nuclear waste disposal

Editorial handling: P. Bossart and A. G. Milnes.

This is paper \#20 of the Mont Terri Special Issue of the Swiss Journal of Geosciences (see Bossart et al. 2017, Table 3 and Fig. 7).

Olivier X. Leupin

olivier.leupin@nagra.ch

1 National Cooperative for the Disposal of Radioactive Waste NAGRA, Hardstrasse 73, 5430 Wettingen, Switzerland

2 Paul Scherrer Institut PSI, 5232 Villigen, Switzerland

3 Institute of Geological Sciences, University of Bern, Baltzerstrasse 3, 3012 Bern, Switzerland

4 Institute of Environmental Assessment and Water Research IDAEA-CSIC, Calle Jordi Girona 18-26, 08034 Barcelona, Spain

5 Associated Unit: Hydrogeology Group (UPC-CSIC), 08034 Barcelona, Spain

\section{Introduction}

Claystone formations are considered worldwide as potential host rocks for the deep geological disposal of radioactive waste. They generally act as aquitards or aquicludes because of their very low hydraulic conductivities, which result from the very small pore and particle sizes. Thus, molecular diffusion is the dominant transport mechanism in these formations under natural conditions (Van Loon et al. 2003; Patriarche et al. 2004; Lavastre et al. 2005; Hendry and Wassenaar 2005; Gimmi et al. 2007; Savoye et al. 2008; Koroleva et al. 2011; Mazurek et al. 2011). Claystone formations also exhibit a large retention potential for sorbing solutes due to the large reactive surface areas of the clay minerals. These properties have triggered an intensive research programme at both laboratory and field scales in the last years. In this regard, the international Mont Terri Project with its underground research laboratory in the Swiss Jura Mountains near St-Ursanne offers a unique platform for improving the understanding of the transport and retention properties of indurated clays. This paper aims to review the main findings and the progress made in the understanding of diffusion and retention processes in Opalinus Clay at the Mont Terri rock laboratory.

Several field diffusion experiments have been performed in the Mont Terri rock laboratory (see Fig. 1; Table 1). The main motivations for conducting diffusion experiments at field scale to complement laboratory-scale experiments, in addition to the large volume of rock that can be investigated, are (a) the very low water/rock ratio leading to a better control of the chemical conditions by the rock and (b) the in situ head pressure which is closer to the disposal situation.

The experiments all served to investigate the in situ transport properties of Opalinus Clay (e.g. Palut et al. 2003; Van Loon et al. 2004b; Wersin et al. 2004; Yllera et al. 


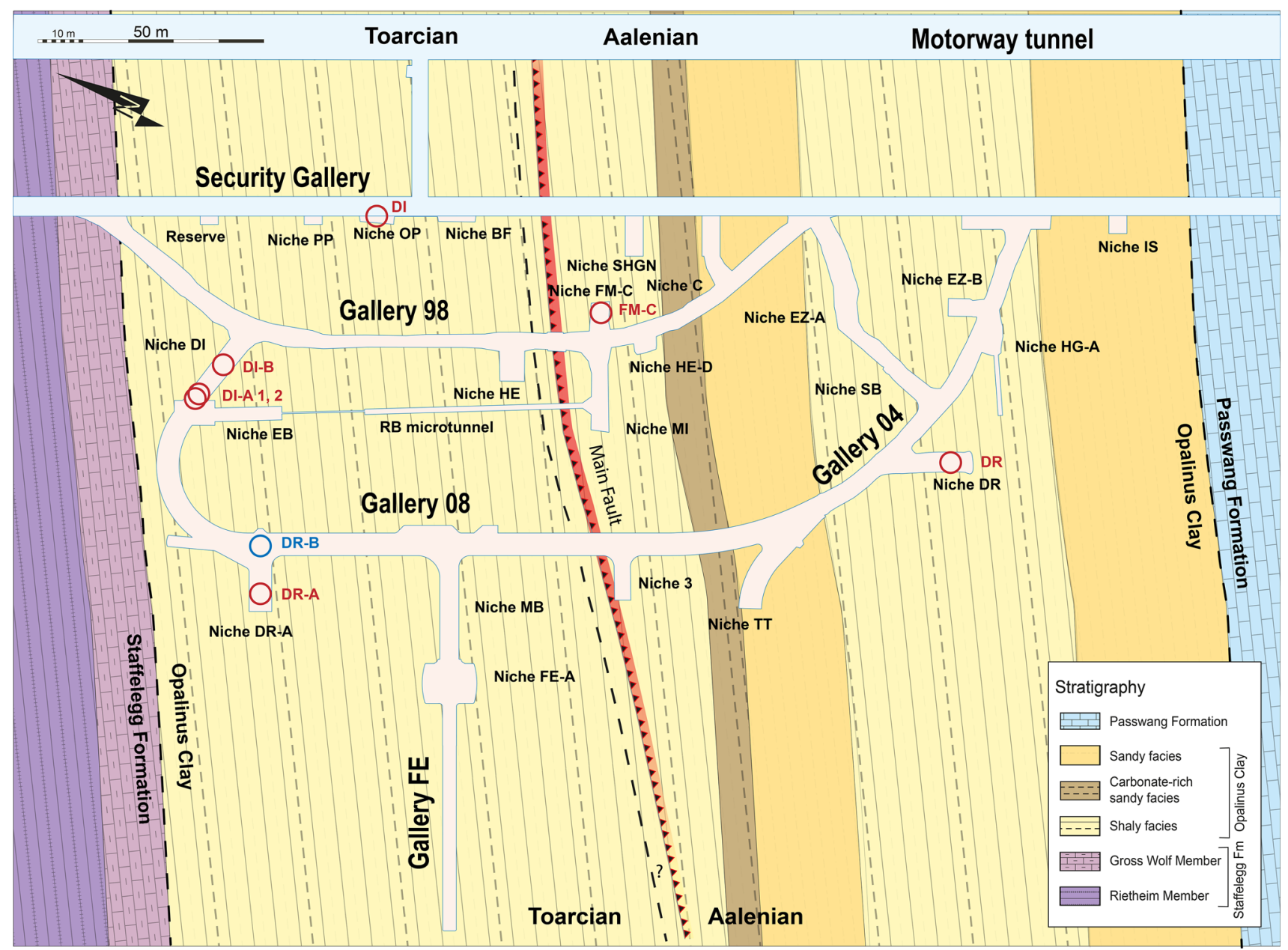

Fig. 1 Map of the Mont Terri rock laboratory indicating the location of the different diffusion experiments

2004; Wersin et al. 2008; Gimmi et al. 2014). A main interest was the comparison of results with those from laboratory experiments performed on small samples (in the order of a few $\mathrm{cm}$ ) of the same material. For instance, small laboratory samples may be strongly affected by stress release, meaning that the obtained parameters are not representative for in situ conditions. Representativeness was also an issue for the in situ tests. One of the field studies (Palut et al. 2003) suggested the existence of a borehole disturbed zone (BdZ), but all the other studies (Van Loon et al. 2004b; Wersin et al. 2004; Soler et al. 2008; Wersin et al. 2008; Gimmi et al. 2014) did not report such an effect. Even though some differences in transport and retention properties were observed, the laboratory values obtained in smaller-scale diffusion experiments could generally be confirmed. For instance, similar diffusion coefficients to those in laboratory studies were obtained in the FM-C, DI, DI-A1, ${ }^{1}$ DI-A2 and DI-B

\footnotetext{
${ }^{1}$ DI-A1 and DI-A2 were two distinct experiments that were administrated within the Mont Terri DI-A project.
}

experiments (for locations see Fig. 6 in Bossart et al. 2017) for tritiated water $\mathrm{HTO}, \mathrm{I}^{-}$and ${ }^{22} \mathrm{Na}^{+}$(Palut et al. 2003; Gómez-Hernández and Guardiola-Albert 2004; Tevissen et al. 2004; Van Loon et al. 2004b; Wersin et al. 2008; Soler et al. 2008). Most of the field experiments in Opalinus Clay used relatively long injection intervals $(\sim 1 \mathrm{~m})$ and were thus dominated by diffusion parallel to the bedding plane of the clay formation. Only the more recent DR experiment (Gimmi et al. 2014) focused on diffusion perpendicular to bedding and on the anisotropy of diffusion.

\section{Concept and modelling of the diffusion experiments}

The general concept of most field diffusion experiments at the Mont Terri rock laboratory is based on the layout used in the first DI experiment (Palut et al. 2003), which was a variation of the decreasing source concentration method used in laboratory column experiments (Rowe et al. 1988; Shackelford 1991). The same general principle was followed 
in earlier in situ large-scale experiments in the Boom Clay Formation in Belgium (Put et al. 1993; De Cannière et al. 1996; Aertsens et al. 2013). In those experiments, tracers (HTO, ${ }^{125} \mathrm{I}^{-}$) were injected in a borehole interval and their concentrations monitored in other intervals of the same borehole. In the experiments at Mont Terri, a tracer cocktail is circulated into a hydraulically packed-off borehole from where the tracers diffuse through a filter screen into the Opalinus Clay. The pressure head of the fluid is maintained at a value close to that of the surrounding pore-water to avoid any advective transport. The decrease in the concentration of the tracers in the circulation system of the borehole is monitored over time until the end of the experiment. At that time, a volume of rock around the borehole interval is overcored and tracer distribution profiles in the rock are measured. The two sets of independent data (temporal evolution in the borehole and spatial distribution profiles in the rock) allow determination through modelling of (a) a transport parameter (effective diffusion coefficient) and (b) an accessible porosity (conservative tracers) or sorption parameter (sorbing tracers). Figure 2 shows results from the DI-A2 experiment (Wersin et al. 2008).

In general, the models used to interpret the measured data solve the diffusion-sorption equation

$\frac{\partial C_{\text {tot }}}{\partial t}=\nabla \cdot\left(\mathbf{D}_{\mathbf{e}} \nabla C\right)$

with $C_{\text {tot }}$ the total solute concentration (including the sorbed fraction), $C$ the aqueous solute concentration, $t$ the time, and $\mathbf{D}_{\mathbf{e}}$ the effective diffusion coefficient tensor. Models for sorbing tracers often assume a linear isotherm (Van Loon et al. 2004b; Wersin et al. 2008, 2010; Gimmi et al. 2014), leading to a constant distribution coefficient $K_{d}$ and a constant rock capacity factor $\alpha$ according to

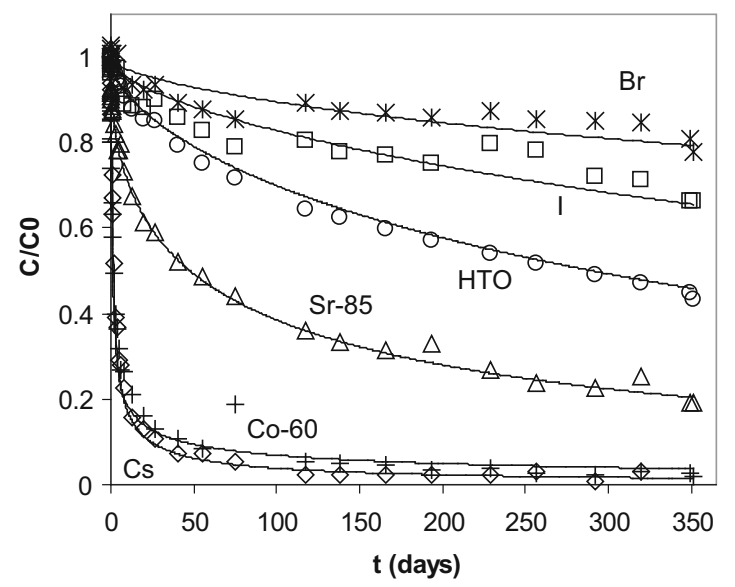

Fig. 2 Experimental and model results from DI-A2 (after Wersin et al. 2008). Evolution of the concentration of the tracers (Br, I, HTO, ${ }^{85} \mathrm{Sr},{ }^{60} \mathrm{Co}$, Cs) in the injection system (relative concentration vs. time) (left). Experimental data (symbols) and modelled concentrations (lines). HTO profiles in the rock (concentration vs. distance from $\alpha=\varepsilon+\rho_{\mathrm{bd}} K_{d}$

and

$C_{\mathrm{tot}}=\alpha C$

with $\varepsilon$ the (accessible) porosity and $\rho_{b d}$ the bulk dry density of the rock. A Freundlich type isotherm or multi-site ion exchange was considered in other cases (above references and Soler et al. 2013, 2014; see also below). The decrease in tracer concentration in the borehole depends directly on both $\mathbf{D}_{\mathbf{e}}$ and $\alpha$ ( $\varepsilon$ for conservative tracers), while transport distances in the rock depend on the magnitude of the apparent diffusion coefficient $D_{a}=\mathbf{D}_{\mathbf{e}} / \alpha$. In this way, both $\mathbf{D}_{\mathbf{e}}$ and $\alpha$ can be determined for each tracer by simultaneously adjusting the model to both sets of data.

The geometrical and conceptual complexity of the models used to analyse and interpret the data from the field experiments have evolved with time. The simulations for the DI, FM-C and (partly) DI-A1 and DI-B experiments were set up in $3 \mathrm{D}$, but it was then recognised that, for the comparably long injection intervals in these experiments, diffusion parallel to bedding dominated the behaviour. Accordingly, later models for the same geometrical setup (DI-A1, DI-A2, DR-A) considered a 1D radial system with diffusion parallel to bedding only, which considerably facilitates simulations. In order to account for the oblique angle of bedding with respect to the vertical borehole axis, a corrected borehole radius had to be adopted.

The borehole for the DR experiment was drilled perpendicular to the bedding. In this case, a 1D radial representation would also be appropriate, but diffusion parallel and perpendicular to bedding had to be considered explicitly for the comparably short intervals, leading to ellipsoidal tracer plumes.

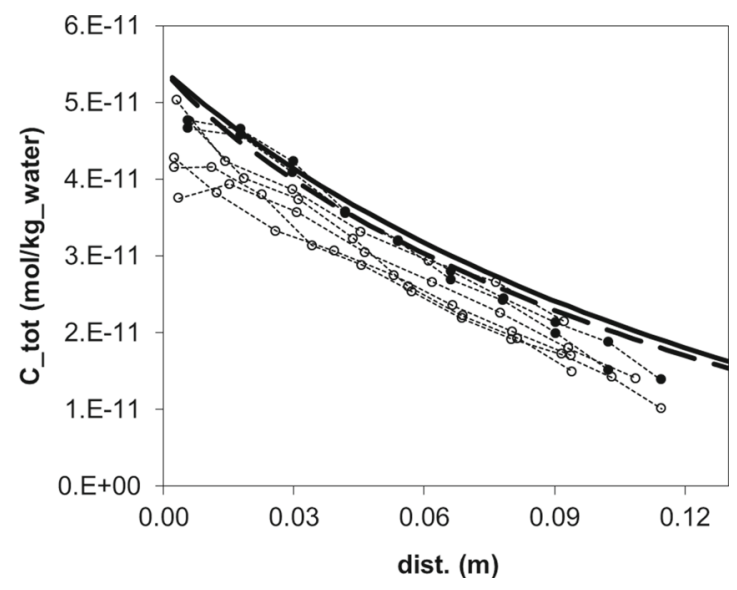

borehole wall) (right). Thin lines and circles represent experimental data; thick line correspond to model results. The 2 uppermost measured profiles (solid circles) were measured around the central part of the circulation interval 
Conceptually, the models for the earlier experiments considered single tracer diffusion only (e.g. Palut et al. 2003; Tevissen et al. 2004; Van Loon et al. 2004b; Yllera et al. 2004; Wersin et al. 2004; Soler et al. 2008; Wersin et al. 2008). That is, transport of a tracer (neutral, anion and/or cation) was assumed to be independent of that of any other solute. This approach was justified for these experiments because the tracers were introduced at low concentrations and the background chemical composition of the pore-water remained practically unaffected.

Stable $\mathrm{Cs}^{+}$in the DI-A1 and DI-A2 experiments, which was injected at concentrations large enough to experience non-linear sorption, was also initially modelled as a single tracer. Non-linear sorption was included through Freundlich sorption isotherms (Van Loon et al. 2004b; Wersin et al. 2004, 2008). Later, a multi-component approach allowed the use of a more mechanistic cation-exchange model (Appelo and Wersin 2007; Appelo et al. 2010; Soler et al. 2013, 2014).

A multi-component approach with interrelated species-specific diffusion of anions and cations (Appelo and Wersin 2007; Appelo et al. 2010) can be considered as more appropriate from a scientific point of view, even though it was not strictly required for the earlier experiments. The strength of such a multi-component approach lies in the fact that the effect of the negatively charged clay surfaces can also be included. These later models considered a diffuse layer region, from which anions are (partly) excluded and where cations are enriched (and contribute to "surface diffusion") compared to bulk pore-water. Inevitably, this multi-porosity approach introduces additional parameters such as the width of the diffuse layer region. These parameters are typically unknown, but there are attempts to determine them from independent data. The DR-A experiment was explicitly set up to test the predictive capability of such multi-component approaches. The strong perturbation of the pore-water chemistry in this experiment requires the coupling between transport and sorption of different ions to be considered and a single-component approach is no longer feasible.

\section{Evolution of the experimental setup}

Table 1 gives an overview of the Mont Terri diffusion experiments performed to date together with the tracers used. The early FM-C experiment was originally planned as a cross-hole tracer test to investigate flow mechanisms in a fracture zone of the main fault area at Mont Terri, but it was then turned into a series of diffusion experiments. In the latest FM-C test (Gómez-Hernández and GuardiolaAlbert 2004), diffusion of HTO and $\mathrm{I}^{-}$through the fracture zone was investigated, starting from a packed-off borehole section around $0.97 \mathrm{~m}$ long.

The main objective of the DI experiment, the pioneer diffusion test, was to develop an experimental concept that would allow a comparison between laboratory and in situ results. It was constructed with two intervals of $0.6 \mathrm{~m}$ length. The lower one was used to inject the tracers (HTO and $\mathrm{I}^{-}$) and the upper one was intended as an observation interval to detect any leakage of tracers along the borehole and packer system. No tracers were detected in the upper interval, meaning that the packer seal was tight and no bypass transport occurred. The setup of the subsequent DIA1, DI-B and DI-A2 experiments consisted of a single interval from which tracers diffused into the rock.

In the DI-A1, DI-B and DI-A2 experiments, the studies were extended to include different sorbing tracers. In addition, DI-B explored the possibility of performing such experiments using only non-active tracers. The setup of these experiments consisted of a single interval from which tracers diffused into the rock.

Two short injection intervals (top and middle, each $0.15 \mathrm{~m}$ long) and a pressure monitoring interval at the bottom $(0.13 \mathrm{~m}$ long $)$ were installed in the DR experiment. The short injection intervals were chosen to be able to determine the diffusion anisotropy in situ and the larger fluid volume in the circulation loop allowed a longer duration of the test (slower decline of tracer concentrations).

The setup of the recent DR-A experiment was a copy of that of the DI-A2. The DR-A experiment aimed at testing multi-component reactive transport models by inducing a strong salinity perturbation after a first half year of tracer indiffusion. The soon to be started diffusion test DR-B is planned as a very long-term, low-maintenance experiment and requires a fundamentally different experimental design in which no fluid would circulate and no active tracers would be needed. The main focus of this diffusion test is to validate diffusion process understanding by using an alternative experimental setup, longer diffusion periods and larger rock volumes. A central borehole was drilled with sufficiently large dimensions to allow emplacement of a source containing a $2 \mathrm{M}$ NaI solution that will provide a diffusion gradient that can be followed over at least a decade from observation boreholes placed at different distances. For this purpose, a highly sensitive, comparably small and mobile XRF probe was developed to follow the diffusion of iodide and other tracers that may be injected in the future.

\section{Analytical methods}

All experiments except DR-B involved the circulation of a solution through the injection interval. Samples of the circulated solutions were regularly taken from the return- 


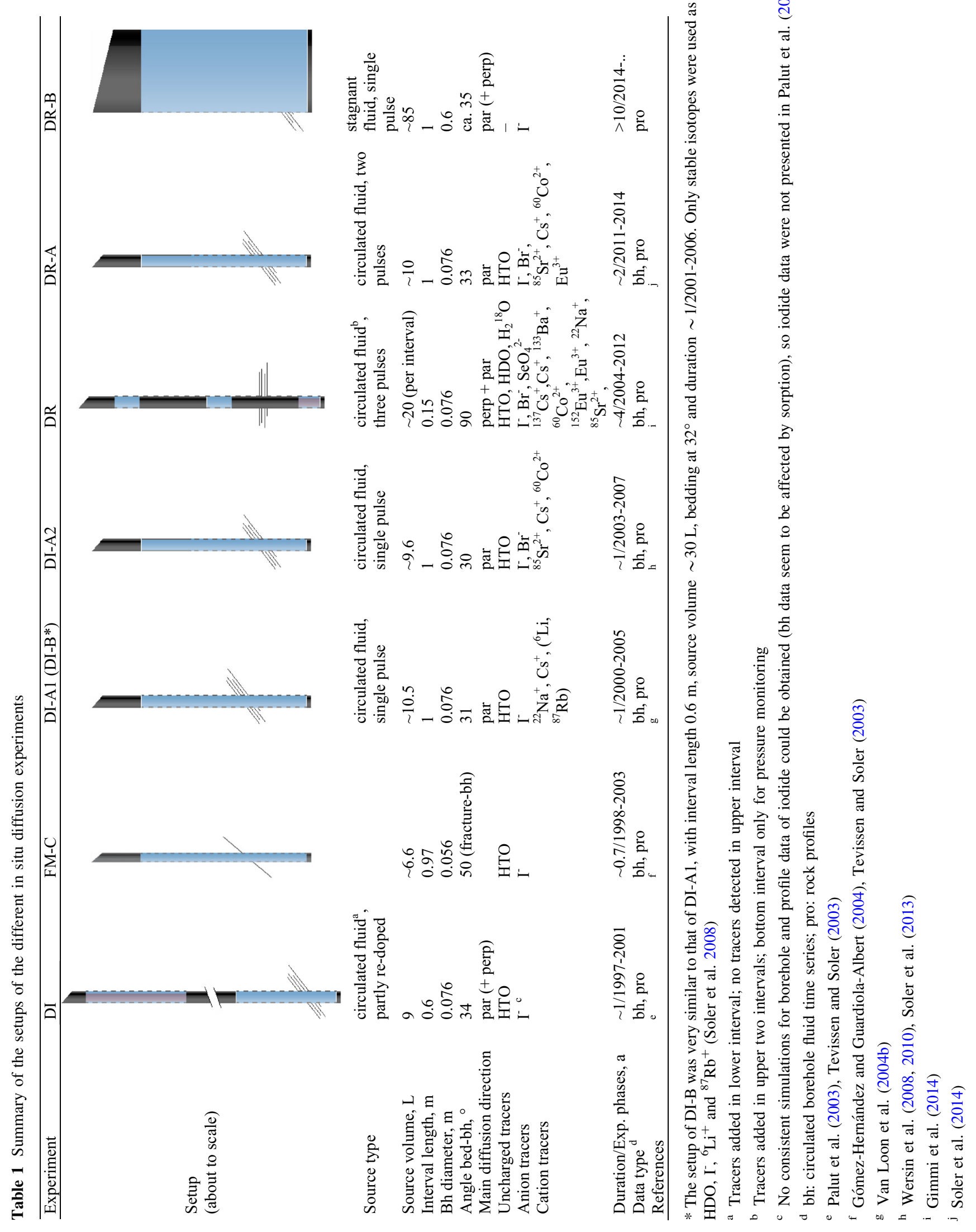


flow lines and analysed for tracers and partly for major components. Usually no fluid was replaced after sampling, which led to a reduction of the total fluid volume in the circulation loops (e.g. by $6-7 \%$ in the case of the DR experiment) by the end of the experiment. In the DI experiment, it was first attempted to keep the HTO activity approximately constant by regularly re-spiking the circulated solution. However, this procedure turned out to be impractical and it was abandoned after three re-spiking events. In addition to the sample data, time series of radioactive tracer activities within the circulated solutions were obtained by $\gamma$ spectrometry (Wersin et al. 2008) in the DI-A2 and the DR experiments.

\subsection{Major element chemistry of water samples}

In most experiments, the major element and tracer composition of collected borehole water was analysed by ion chromatography (IC), inductively coupled plasmaoptical emission spectroscopy (ICP-OES) and/or inductively coupled plasma-mass spectrometry (ICP-MS). Details of the determination of ions are given in Palut et al. (2003), Van Loon et al. (2004b), Wersin et al. (2004, 2008), Soler et al. (2008) and Gimmi et al. (2014). Most of the samples were filtered $(0.45$ or $0.2 \mu \mathrm{m})$ prior to analysis. Using these techniques, analytical uncertainties are in the range of $\pm 10 \%$ for $\mathrm{Cl}^{-}$ and $\mathrm{Na}^{+}$and $\pm 5 \%$ for all other tracers and solutes. Alkalinity was generally determined for selected samples by potentiometric titration. In some experiments, $\mathrm{pH}$ was measured in the laboratory and in-line with a combined glass electrode (high-pressure resisting KCl-type gel electrolyte containing glycerol) and $E_{\mathrm{h}}$ was obtained inline with an $\mathrm{Ag} / \mathrm{AgCl}$ electrode $(3 \mathrm{M} \mathrm{KCl}$ gel type, reference potential of $+0.210 \mathrm{~V}$ ).

\subsection{Off-line analyses of radiotracers in water samples}

Samples of the water circulating through the borehole interval were taken at different times during the experiments to monitor the decrease in tracer concentrations. Activities of ${ }^{75} \mathrm{SeO}_{4}{ }^{2-},{ }^{22} \mathrm{Na}^{+},{ }^{85} \mathrm{Sr}^{2+},{ }^{133} \mathrm{Ba}^{2+},{ }^{137} \mathrm{Cs}^{+}$, ${ }^{60} \mathrm{Co}^{2+}$ and ${ }^{152} \mathrm{Eu}^{3+}$ in filtered $(0.45 \mu \mathrm{m})$ borehole water samples were determined by $\gamma$-ray counting with two high-resolution intrinsic p-type coaxial Ge-detectors at the radio-analytical laboratory of the Paul Scherrer Institute. The HTO activity concentrations of the same solutions were obtained by liquid scintillation counting (LSC) at the same laboratory. The analytical uncertainties were estimated to be about $\pm 3 \%$ for HTO, between \pm 5 and $\pm 15 \%$ for ${ }^{22} \mathrm{Na}^{+}$( $\beta$-emitter) and $\pm 5 \%$ for the other radiotracers.

\subsection{In-situ analyses of radiotracers in reservoir tanks}

In the DI-A2 and DR experiments, the depletion of radiotracers in the circulating fluid was also measured in situ using a solid-state intrinsic high-purity Ge-detector with an electric cryo-cooling system (Wersin et al. 2008) which was placed in between (DR) or juxtaposed (DI-A2) to the tracer reservoirs. The following tracers could be tracked in the circulating fluid: ${ }^{75} \mathrm{SeO}_{4}{ }^{2-},{ }^{22} \mathrm{Na}^{+},{ }^{85} \mathrm{Sr}^{2+},{ }^{133} \mathrm{Ba}^{2+},{ }^{137} \mathrm{Cs}^{+},{ }^{60} \mathrm{Co}^{2+}$ and ${ }^{152} \mathrm{Eu}^{3+}$. The Ge-detector had to be regularly dismantled for maintenance, which resulted in small gaps in the time series and slight shifts in the measurements after re-installation; these were attributed to slightly different sensitivities and measurement geometries of the device. The ${ }^{40} \mathrm{~K}$ background signal was used to recalibrate the data after re-installation.

\subsection{Profile data}

Tracer profiles in the claystone were essential in order to estimate transport parameters (e.g. HTO, $\mathrm{I}^{-}, \mathrm{Br}^{-},{ }^{22} \mathrm{Na}^{+}$ and others) and water content unambiguously. The behaviour of the different mobile tracers could be compared directly when plotting the radial and axial profiles using normalised concentrations.

Therefore, after termination of the experiments the diffusion test intervals were usually overcored to analyse tracer distribution in the rock. The overcoring technique itself evolved over time and had to be adapted to the diffusion test geometries and boundary conditions (e.g. the inclined central borehole in the DR experiment required an oblique overcoring and the long duration of DR-A required an excentric overcore to maximise the sampling distance). The overcore was typically obtained a few days after taking the last sample from the circulation loop. The overcore was then sub-sampled immediately on site, as far as possible, by cutting disks parallel (e.g. DR experiment) or oblique (e.g. FM-C experiment) to the bedding or by drilling subcores (DI-A1, DI-A2). These disks and sub-cores were then further dimensioned to a practical size for the specific analyses. Detailed information on the analytical programme for the sub-samples can be found in e.g. Gimmi et al. (2014). In general, and depending on the specific composition of the circulating fluid, water content, stable water isotopes, active tracers and major element composition of the aqueous extracts were analysed.

\section{Compilation of experimental results}

The diffusion and sorption parameters obtained from numerical modelling exercises in the DI, DI-A1, DI-B, DIA2 and DR experiments are compared with diffusion data 
from oriented small-scale samples parallel to the bedding plane (Van Loon and Soler 2003; Van Loon et al. 2004b) and with laboratory batch sorption data (Van Loon et al. 2005a). As shown in Table 2, this comparison shows an overall consistent picture between laboratory and in situ results (details discussed below).

For all diffusion experiments carried out so far, except for DR-A, the circulating artificial water was prepared to match approximately the in situ pore-water composition. The borehole waters, which were sampled regularly, indicated fairly constant compositions, consistent with that expected for the pore-water. This confirms that the added artificial pore-water affected chemical conditions to only a small extent, thus ensuring stable chemical conditions. It is noteworthy that most of the added tracers (i.e. HTO, $\mathrm{I}^{-}, \mathrm{Br}^{-}$, $\mathrm{Na}^{+}, \mathrm{Sr}^{2+}, \mathrm{Cs}^{+}$) were not, or only barely, sensitive to $\mathrm{pH}$ or $\mathrm{Eh}$, and thus perturbation of the $\mathrm{pH}$ or redox conditions should not have altered their diffusion behaviour. However, disturbance of salinity will affect cationic and anionic tracers to some extent and this was demonstrated in the DR-A experiment. A redox disturbance was unintentionally caused in the upper borehole section of the DR experiment by leakage of glycerol from the $\mathrm{pH}$ electrode (Gimmi et al. 2014). This resulted in microbially induced sulphate reduction and sulphide generation. Tracer data indicated that this led to the precipitation of CoS but did not affect the diffusion of the other injected tracers (Gimmi et al. 2014).

\subsection{Water tracer diffusion}

For HTO (and HDO in the DI-B and DR experiments, with D being ${ }^{2} \mathrm{H}$ ), the derived values for effective diffusivity and porosity show good agreement between in situ and laboratory data, well within the uncertainty of these parameters. A more detailed analysis of the HTO profiles in the DI-A2 experiment shows that the concentrations in the profiles measured around the upper and lower parts of the injection interval are slightly smaller than those in the central part of the interval (length $=1 \mathrm{~m}$; Fig. 2). This fact may suggest that transport distances for HTO were large enough to start noticing the effect of diffusion in the direction normal to bedding. This trend was not obvious for $\mathrm{I}^{-}, \mathrm{Br}^{-}$or ${ }^{85} \mathrm{Sr}^{2+}$. In DI-A2, some evidence was found related to erosion of the borehole wall in the upper and lower parts of the borehole that could also result in the observed differences in the diffusion profiles (Wersin et al. 2008).

Most HTO profiles in the DI, DI-A1, DI-A2 and DR experiments (and HDO in DI-B) show a slightly flatter region (low concentrations compared to model curves) next to the injection borehole (Fig. 2). This feature could in principle be related to (1) a $\mathrm{BdZ}$, with somewhat increased diffusion coefficients and porosity; (2) evaporation of HTO during the overcoring procedure; (3) back-diffusion of
HTO into the resin while it was hardening, ${ }^{2}$ possibly supported by the increased temperature. The occurrence of a $\mathrm{BdZ}$ was reported only in the DI experiment, mainly based on a higher rate of out-diffusion at earlier times compared to later times. It was not reported in any of the other experiments, where the drilling disturbance was kept to a minimum by installing the packer system and filling the interval section quickly after drilling. Also, a BdZ would in fact lead to slightly higher HTO concentrations close to the borehole interface compared to model results for uniform rock properties, in contrast to what was observed. Thus, process (1) is not a likely cause of the observed feature of the HTO profiles. Evaporation of water close to the borehole wall would also lead to a potential increase in the HTO concentrations due to the fractionation of ${ }^{3} \mathrm{H}$ into the remaining liquid phase. Moreover, the external rims of the overcores, which were exposed to air for the longest times, did not show any noticeable anomaly. Accordingly, evaporation can also not explain the observation. A slight outdiffusion of HTO into the (not yet hardened) resin was therefore considered as a possible cause for the observed slight flattening of the HTO profiles near the borehole interface and the overestimation of the concentrations when modelling the data. It is possible that HTO shows a higher solubility in the resin compared to other tracers, which would make HTO more sensitive to such out-diffusion. Unfortunately, no resin was sampled to test its HTO content in any of the experiments.

\subsection{Anionic tracer diffusion}

The effective diffusion coefficients for the anionic tracers $\mathrm{I}^{-}$and $\mathrm{Br}^{-}$are systematically smaller than those for the water tracers HTO and HDO. The same trend is manifested for the diffusion-accessible porosities. The diffusion coefficients obtained for $\mathrm{Br}^{-}$and $\mathrm{I}^{-}$in the DI-A2 experiment were somewhat higher than those from other in situ experiments (DI-A1, DR, DI-B, FM-C) and laboratory diffusion tests (Table 2). In the case of $\mathrm{Br}^{-}$, this observation may be related to the higher uncertainty in experimental data arising from the low ratio between tracer to background concentrations. Note that identical parameters were obtained for $\mathrm{Br}^{-}$and $\mathrm{I}^{-}$in spite of the slightly slower decrease of bromide concentration in the borehole. This difference is fully explained by the smaller concentration gradient due to the higher background concentration of $\mathrm{Br}^{-}$ in the pore-water. Note also that, for DI, the derived diffusivities and porosities show a large uncertainty, which is related to the $\mathrm{BdZ}$ created during borehole construction and

\footnotetext{
${ }^{2}$ Immediately after the dismantling of the packer system, the central borehole was filled with sand and resin to stiffen the borehole before overcoring.
} 


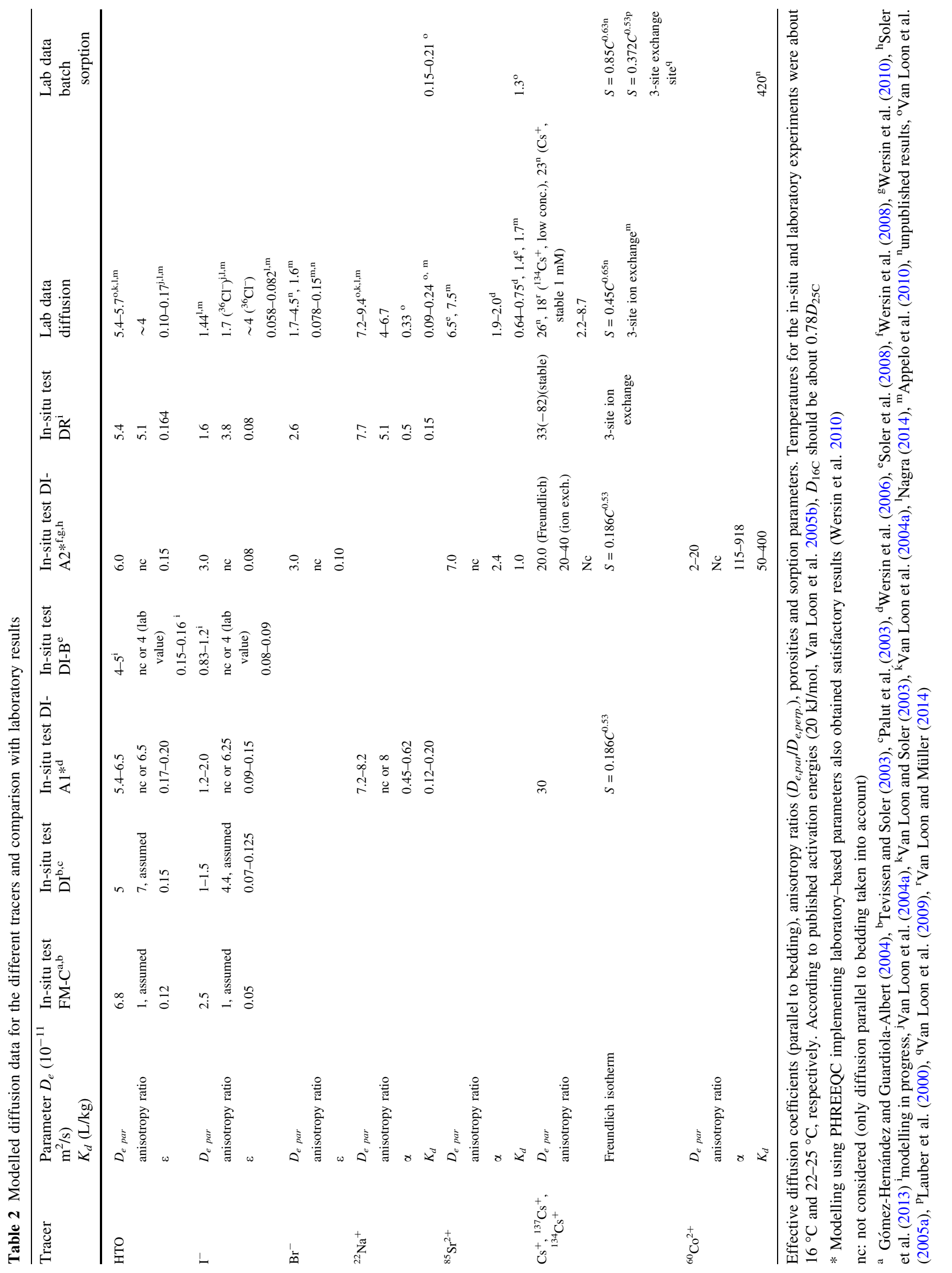


installation (Tevissen et al. 2004). The smaller effective diffusion coefficients and diffusion-accessible porosities of anions compared to water tracers and cations is explained by repulsion of anions from the negatively charged clay surfaces, which leads to a deficit of anions relative to cations in the electric double layers (EDLs). This anion exclusion effect is commonly approximated by the concept of anion-accessible porosity (Pearson 1999; Pearson et al. 2003), although in reality the decrease towards the negatively charged surface is a continuum rather than a step function. The anion-accessible porosity fraction calculated from the ratio of the porosities of $\mathrm{I}^{-}$and HTO (HDO in DIB) for DI-A1, DI-A2, DI-B, FM-C and DR is $0.55 \pm 0.014$. This value is in good agreement with porosities obtained in laboratory experiments and indicates the good quality of the derived porosities and a relatively small variation in the anion porosity fraction at Mont Terri. Similar anion-accessible porosities were obtained from a previous compilation of Mont Terri data (Pearson et al. 2003) and also for Opalinus Clay in north-east Switzerland (Gimmi and Waber 2004; Wersin et al. 2013). According to the double layer theory, this parameter should vary with ionic strength; thus, at lower ionic strength the thickness of the EDL should increase, which would lead to a decrease in the anion-accessible porosity fraction. This effect is not observed in the in situ diffusion experiments. The difference in ionic strength seems to be too small (maximum of a factor of roughly 2 (Gimmi et al. 2014)) to be able to observe any effect, given the experimental uncertainty.

\subsection{Cation diffusion coefficients}

As illustrated in Table 2, the diffusion coefficients of $\mathrm{Na}^{+}, \mathrm{Sr}^{2+}$ or $\mathrm{Cs}^{+}$tracers from the field experiments are relatively large when compared to those of HTO. This is in agreement with laboratory studies on montmorillonite, bentonite and other clay-rich rocks (e.g. Glaus et al. 2010; Gimmi and Kosakowski 2011; Tachi et al. 2011; Tachi and Yotsuji 2014). The comparably large values may be explained by the so-called surface diffusion of sorbed cations (including cations in the diffuse layer and in interlayers), which leads to an additional driving force for diffusion besides the pore-water gradient (e.g. Glaus et al. 2013). From a normalisation of a large number of published tracer cation diffusion data, Gimmi and Kosakowski (2011) could show that normalised effective cation diffusion coefficients $D_{\text {erw }}$ generally increase with a normalised sorption capacity of the cation. The latter was calculated as $\kappa=\rho_{\mathrm{bd}} K_{d} / \varepsilon$ and $D_{\text {erw }}=D_{e} \tau_{\mathrm{w}} /\left(D_{0} \varepsilon_{\mathrm{w}}\right)$, with $\tau_{\mathrm{w}}$ the tortuosity and $\varepsilon_{\mathrm{w}}$ the porosity obtained for a water tracer. Values of $D_{\text {erw }}$ larger than 1 point to a contribution of surface diffusion. They also derived average surface mobilities (surface diffusion coefficient

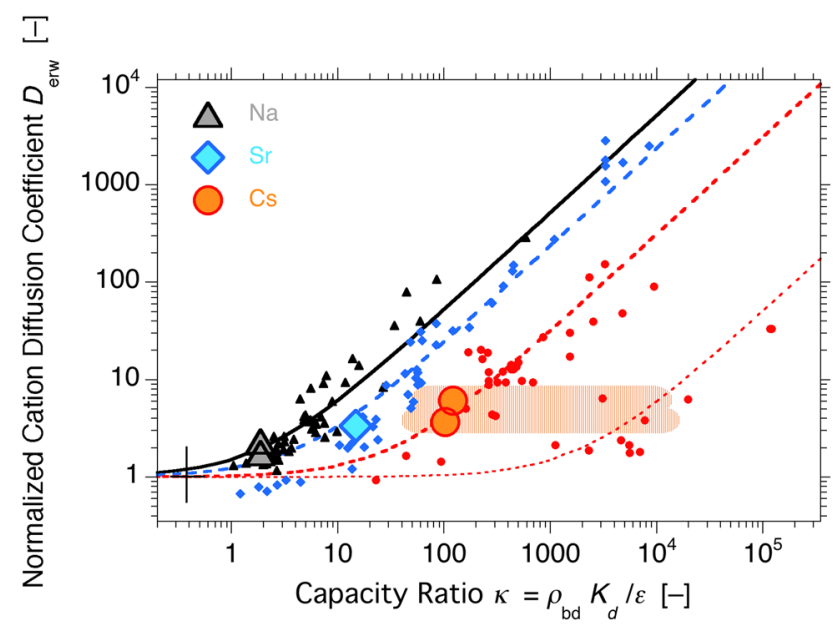

Fig. 3 Normalised cation diffusion coefficients $D_{\text {erw }}$ for $\mathrm{Na}^{+}, \mathrm{Sr}^{2+}$ and $\mathrm{Cs}^{+}$plotted as a function of the normalised sorption capacity $\kappa=\rho_{\text {bd }} K_{d} / \varepsilon$. Small symbols literature values for tracers compiled by Gimmi and Kosakowski (2011); lines model (Gimmi and Kosakowski 2011). For Cs, two lines are drawn according to two subsets of the data as identified in Gimmi and Kosakowski (2011): thicker line for data obtained at comparably high (but constant) Cs background concentrations or for samples without illite, thinner line for data obtained at $\mathrm{Cs}$ trace concentrations in samples containing illite (thus probably strongly influenced by frayed edge sites). Large symbols and shaded area $D_{\text {erw }}$ derived from results of Mont Terri field experiments (Van Loon et al. 2004b; Wersin et al. 2008, partly re-analysed). In the field experiments, the Cs concentration was not constant: initially comparably high, then quickly decreasing to lower values. This leads to $K_{d}$ values varying in time and space due to non-linear (multi-site) sorption. The large symbol for Cs is drawn at the average $K_{d}$ value, the shaded area encompasses the relevant $K_{d}$ range

on a flat surface normalised to bulk water diffusion coefficient) for various cations. Different surface mobilities, which represent averages for all relevant sorption sites in multi-site sorption, were derived for $\mathrm{Na}^{+}, \mathrm{Sr}^{2+}$, $\mathrm{Ca}^{2+}$ and $\mathrm{Cs}^{+}$. Figure 3 shows a plot of normalised $\mathrm{Na}^{+}$, $\mathrm{Sr}^{2+}$ and $\mathrm{Cs}^{+}$cation diffusion coefficients $D_{\text {erw }}$ against the normalised sorption capacity $\kappa=\rho_{\text {bd }} K_{d} / \varepsilon$. The literature values compiled by Gimmi and Kosakowski (2011) are shown as small symbols and their modelled curves as lines; the results of the Mont Terri field experiments for $\mathrm{Na}^{+}, \mathrm{Sr}^{2+}$ and $\mathrm{Cs}^{+}$(Van Loon et al. 2004b; Wersin et al. 2008; partly re-analysed) are shown as large symbols. From this Figure, the following can be concluded: (1) Firstly, the normalised diffusion coefficients for $\mathrm{Na}^{+}, \mathrm{Sr}^{2+}$ and $\mathrm{Cs}^{+}$derived from the values obtained in the Mont Terri field experiments are in accordance with the trends of other published (mostly laboratory) data, for instance those of Melkior et al. (2005) (for all references see Gimmi and Kosakowski 2011). (2) Secondly, the normalised diffusion coefficients for $\mathrm{Na}^{+}, \mathrm{Sr}^{2+}$ and $\mathrm{Cs}^{+}$in the field experiments are somewhat increased $\left(D_{\text {erw }}>1\right)$, which points to a contribution from surface diffusion. The extent of this 
increase is, however, relatively small compared to some of the other (laboratory) data for other materials. This is mainly related to the in situ pore-water composition in the field experiments, with an ionic strength in the order of $0.2-0.4 \mathrm{M}$ (the ionic strength was usually adjusted to the specific location of the test in the Mont Terri rock laboratory). The largest normalised effective cation diffusion coefficients shown in Fig. 3 (see references in Gimmi and Kosakowski 2011) are typically observed for relatively dilute solutions (with low ionic strength). (3) Thirdly, the $\mathrm{Cs}^{+}$field diffusion coefficients cannot be uniquely represented in such a plot that depends on a single $K_{d}$ value. This is because the $\mathrm{Cs}^{+}$concentration varied considerably during the field experiments, which affects the degree of sorption in a non-linear way and leads to a $K_{d}$ that varies in the experiment with space and time. Figure 3 shows the $D_{e}$ for $\mathrm{Cs}^{+}$plotted at the capacity ratio obtained from an average $K_{d}$, with a shaded area covering the possible range of $K_{d}$ values. In the DR experiment, caesium showed different penetration distances for the stable $\mathrm{Cs}^{+}$ added at high concentrations in the upper interval and for the ${ }^{137} \mathrm{Cs}^{+}$added at trace concentrations in the lower interval. This behaviour confirms the non-linear nature of $\mathrm{Cs}^{+}$sorption in Opalinus Clay also observed in e.g. the DI-A1 and DI-A2 experiments and in laboratory sorption experiments (Lauber et al. 2000). $\mathrm{Cs}^{+}$sorption was first assumed to follow a Freundlich isotherm (Lauber et al. 2000; Van Loon et al. 2004b) in DI-A1 and DI-A2, or a 3 -site cation-exchange process (Bradbury and Baeyens 2000; Van Loon et al. 2009; Jakob et al. 2009) later in DI-A2 and DR (Soler et al. 2013; Gimmi et al. 2014). The sorption behaviour could be well described by a Freundlich-type adsorption isotherm in DI-A1 and DI-A2, although there was a clear tendency towards a decreased sorption capacity in the field diffusion experiments relative to the batch sorption data. This tendency, however, may be the result of an inconsistent treatment of diffusion through the filter in the model of the DI-A1 and DI-A2 field experiments, even though other reasons (uncertainty in selectivities, incomplete initial mixing) may also apply (Soler et al. 2013). For cobalt, so far there are no other diffusion data with which to compare the field results. Given the different profiles measured in the rock in the DI-A2 experiment, different combinations of $D_{e}$ and $K_{d}$ are possible. However, the $K_{d}$ values tend to be smaller than those obtained from batch sorption experiments for similar geochemical conditions $(420 \mathrm{~L} / \mathrm{kg}$, unpublished results, see Table 2). When $D_{e}$ and $\varepsilon$ for $\mathrm{Co}^{2+}$ are set to the same values as for HTO, a $K_{d}$ value of about $90 \mathrm{~L} / \mathrm{kg}$ is obtained. Thus, the sorption of this tracer may be smaller in intact rock than in crushed rock (batch experiments) but, in view of the large scatter in the rock profiles for DI-A2 and the scarce laboratory data, it is not possible to draw definite conclusions.

\subsection{Porosities}

A $\mathrm{Cl}^{-}$-accessible porosity of 0.09 ( 0.55 of the average water-loss porosity of 0.164 ) was reliably estimated from a comparison of the equilibrated $\mathrm{Cl}^{-}$concentrations in the rock and in the borehole fluid in the DR experiment. The same value was also applicable for $\mathrm{Br}^{-}$and $\mathrm{I}^{-}$. The value seems to be unaffected by the lower ionic strength at the location of the DR experiment compared to the earlier DI$\mathrm{A}$ and DI-B experiments.

\subsection{Anisotropy factor}

Anisotropy ratios were obtained in situ for the first time in the DR experiment. They were found to be slightly larger for HTO and ${ }^{22} \mathrm{Na}^{+}(\sim 5.1 \pm 0.5)$ as compared to the anions $\left(\sim 3.8 \pm 0.4\right.$ for $\mathrm{I}^{-}$and $\sim 2.6 \pm 0.4$ for $\left.\mathrm{Br}^{-}\right)$, which may be related to the exclusion of anions from the narrowest, well oriented pores. The design of the other in situ experiments did not allow anisotropy factors to be derived. The diffusion anisotropy ratios are slightly larger than (HTO), similar to (I), or slightly lower ( $\mathrm{Br})$ than values obtained in the laboratory (Van Loon et al. 2004a) for ${ }^{36} \mathrm{Cl}^{-}$and HTO in Opalinus Clay from Mont Terri (Gimmi et al. 2014).

\subsection{Borehole disturbed zone}

The profile data in the DI-A1, DI-B, DI-A2 and DR experiments did not indicate the presence of a $\mathrm{BdZ}$, in contrast to the data from the DI experiment. In the DR experiment, the model of tracer fluid data only suggested the possibility of a $\mathrm{BdZ}$ in the range of 1 to $1.5 \mathrm{~cm}$ around the lower interval. Such a strongly disturbed zone was, however, clearly not visible in the profile data.

\section{Conclusions}

Due to steadily evolving experimental designs, similar tracer compositions in different experiments and complementary small laboratory-scale diffusion tests, a unique and comprehensive database for diffusion and sorption of both chemically conservative and reactive nuclides under in situ conditions could be compiled for an indurated argillaceous rock. Such a database is a key component of the safety case for a repository for radioactive waste in claystone.

It could be shown that the sorption and diffusion data from in situ experiments are consistent and also 
comparable with the results obtained from small-scale laboratory experiments.

Values for diffusion-accessible porosities for anions turned out to be consistent within the field experiments and also with the results from laboratory experiments. Anionaccessible porosity seemed to be unaffected by the salinity gradients $(0.22-0.39 \mathrm{M})$ in the Mont Terri rock laboratory and the anisotropy factor (3-4 for anions, 5 for HTO and $\mathrm{Na}^{+}$) agrees well with the values measured in the laboratory. This factor is smaller than that obtained for samples from the Benken borehole in north-east Switzerland (Nagra 2014).

Field experiments have also shown that phenomena such as textural and/or mineralogical heterogeneities, or processes such as the formation of a BdZ do not jeopardise the interpretation of diffusion data as previously feared. Based on the profile data, the DI-A1, DI-B, DI-A2 and DR experiments did not indicate the presence of a $\mathrm{BdZ}$, in contrast to the $\mathrm{BdZ}$ deduced in the $\mathrm{DI}$ experiment. The presence of the latter $\mathrm{BdZ}$ was due to technical issues during the realisation of the borehole (problems with packer installation led to a longer time when the borehole was open to the atmosphere).

The number and duration of the different experiments allowed suitable rock profiles to be obtained, also for strongly sorbing tracers. The observed sequence of penetration depths of the tracers (HTO $>\mathrm{Br}^{-} \geq \mathrm{I}^{-} \geq$ $\mathrm{SeO}_{4}{ }^{2-}>{ }^{22} \mathrm{Na}^{+}>{ }^{133} \mathrm{Ba}^{2+}>\mathrm{Cs}^{+}>{ }^{137} \mathrm{Cs}^{+}>{ }^{60} \mathrm{Co}^{2+}>$ ${ }^{152} \mathrm{Eu}^{3+}$ ) is as expected for the small pore diffusion coefficients of the anions compared to HTO and the increasing retardation by sorption for the cations. Penetration depths for the strongly sorbing tracers did not extend beyond a few centimetres.

Finally, the field diffusion experiments at the Mont Terri rock laboratory not only allowed a good scientific understanding of diffusion processes in claystones to be acquired, but also the development and testing of technological skills required for performing underground diffusion tests. This know-how has been successfully transferred to other underground laboratories (e.g. Delay et al. 2014; Naves et al. 2010).

The field diffusion experiments are of great relevance for the safety case of deep geological repositories. The reasons for this are not related primarily to the parameters derived from such experiments but are as formulated in the introduction, namely (a) complementing laboratory-scale experiments, in addition to the large volume of rock investigated, (b) the very low water/rock ratio leading to better control of the chemical conditions by the rock, and (c) the in situ head pressure being closer to the disposal case. In summary, the diffusion experiments conducted at the Mont Terri rock laboratory have greatly improved the understanding of transport and retention processes and the modelling of these and thus our confidence in Opalinus Clay as a host rock with outstanding safety barrier qualities.

Acknowledgements We thank the swisstopo personnel at St-Ursanne for providing excellent working conditions in the Mont Terri rock laboratory and the many researchers from numerous organisations involved in the work presented in this paper. We also like to express our gratitude to Dr. Christophe Tournassat, French Geological Survey BRGM, Orléans, France and Dr. Sebastien Savoye, CEA, Gif-surYvette for a critical review of the manuscript.

Open Access This article is distributed under the terms of the Creative Commons Attribution 4.0 International License (http://crea tivecommons.org/licenses/by/4.0/), which permits unrestricted use, distribution, and reproduction in any medium, provided you give appropriate credit to the original author(s) and the source, provide a link to the Creative Commons license, and indicate if changes were made.

\section{References}

Aertsens, M., Maes, N., Van Ravestyn, L., \& Brassinnes, S. (2013). Overview of radionuclide migration experiments in the HADES Underground Research Facility at Mol (Belgium). Clay Minerals, 48, 153-166.

Appelo, C. A. J., Van Loon, L. R., \& Wersin, P. (2010). Multicomponent diffusion of a suite of tracers ( $\mathrm{HTO}, \mathrm{Cl}, \mathrm{Br}, \mathrm{I}, \mathrm{Na}, \mathrm{Sr}, \mathrm{Cs})$ in a single sample of Opalinus Clay. Geochimica et Cosmochimica Acta, 74, 1201-1219.

Appelo, C. A. J., \& Wersin, P. (2007). Multicomponent diffusion modeling in clay systems with application to the diffusion of tritium, iodide, and sodium in Opalinus Clay. Environmental Science and Technology, 41, 5002-5007.

Bossart, P., Bernier, F., Birkholzer, J., Bruggeman, C., Connolly, P., Dewonck, S., Fukaya, M., Herfort, M., Jensen, M., Matray, J-M., Mayor, J. C., Moeri, A., Oyama, T., Schuster, K., Shigeta, N., Vietor, T., \& Wieczorek, K. (2017). Mont Terri rock laboratory, 20 years of research: introduction, site characteristics and overview of experiments. Swiss Journal of Geosciences, 110. doi:10.1007/s00015-016-0236-1 (this issue).

Bradbury, M. H., \& Baeyens, B. (2000). A generalised sorption model for the concentration dependent uptake of caesium by argillaceous rocks. Journal of Contaminant Hydrology, 42, 141-163.

De Cannière, P., Moors, H., Lolivier, P., De Preter, P. \& Put, M. (1996). Laboratory and in situ migration experiments in the Boom clay. Nuclear Science and Technology, Report EUR 16927 EN, 74 pp. European Commission, Brussels, Belgium.

Delay, J., Bossart, P., Ling, L. X., Blechschmidt, I., Ohlsson, M., Vinsot, A., et al. (2014). Three decades of underground research laboratories: what have we learned? Geological Society, London, Special Publications, 400, 7-32.

Gimmi, T., \& Kosakowski, G. (2011). How mobile are sorbed cations in clays and clay rocks? Environmental Science \& Technology, 45, 1443-1449.

Gimmi, T., Leupin, O. X., Eikenberg, J., Glaus, M. A., Van Loon, L. R., Waber, H. N., et al. (2014). Anisotropic diffusion at the field scale in a 4-year multi-tracer diffusion and retention experimentI: Insights from the experimental data. Geochimica et Cosmochimica Acta, 125, 373-393.

Gimmi, T. \& Waber, H.N. (2004). Model of tracer profiles in pore water of argillaceous rock in the Benken borehole: stable water isotopes, chloride and chlorine isotopes. Nagra Technical 
Report, 04-05, 105 pp. Nagra, Wettingen, Switzerland. http:// www.nagra.ch

Gimmi, T., Waber, H. N., Gautschi, A., \& Rubel, A. (2007). Stable water isotopes in pore water of Jurassic argillaceous rocks as tracers for solute transport over large spatial and temporal scales. Water Resources Research, 43(4), W04410.

Glaus, M. A., Birgersson, M., Karnland, O., \& Van Loon, L. R. (2013). Seeming steady-state uphill diffusion of ${ }^{22} \mathrm{Na}^{+}$in compacted montmorillonite. Environmental Science and Technology, 47, 11522-11527.

Glaus, M. A., Frick, S., Rossé, R., \& Van Loon, L. R. (2010). Comparative study of tracer diffusion of HTO, ${ }^{22} \mathrm{Na}^{+}$and ${ }^{36} \mathrm{Cl}^{-}$ in compacted kaolinite, illite and montmorillonite. Geochimica et Cosmochimica Acta, 74, 1999-2010.

Gómez-Hernández, J. J. \& Guardiola-Albert, C. (2004). Flow Mechanism (FM-C) Experiment: Three dimensional model predictions of tracer evolution of HTO and iodine in the main fault. Mont Terri Technical Report, TR 2000-08, 21 pp. Federal Office of Topography (swisstopo), Wabern, Switzerland. http:// www.mont-terri.ch.

Hendry, M. J. \& Wassenaar, L. I. (2005). Origin and migration of dissolved organic carbon fractions in a clay-rich aquitard: C-14 and delta C-13 evidence. Water Resources Research 41(2)

Jakob, A., Pfingsten, W., \& Van Loon, L. (2009). Effects of sorption competition on caesium diffusion through compacted argillaceous rock. Geochimica et Cosmochimica Acta, 73, 2441-2456.

Koroleva, M., Alt-Epping, P., \& Mazurek, M. (2011). Large-scale tracer profiles in a deep claystone formation (Opalinus Clay at Mont Russelin, Switzerland): implications for solute transport processes and transport properties of the rock. Chemical Geology, 280, 284-296.

Lauber, M., Baeyens, B. and Bradbury, M. H. (2000). PhysicoChemical Characterisation and Sorption Measurements of Cs, Sr, $\mathrm{Ni}, \mathrm{Eu}, \mathrm{Th}, \mathrm{Sn}$ and Se on Opalinus Clay from Mont Terri. Paul Scherrer Institut Bericht 00-10, 78 pp.Villigen, Switzerland. http://www.psi.ch.

Lavastre, W., Jendrzejewski, N., Agrinier, P., Javoy, M., \& Evrard, M. (2005). Chlorine transfer out of a very low permeability clay sequence (Paris Basin, France): Cl-35 and C-37 evidence. Geochimica et Cosmochimica Acta, 69, 4949-4961.

Leupin, O., Wersin, P., Gimmi, T., Mettler, S., Rösli, U., Meier, O., Nussbaum, C., Van Loon, L., Soler, J., Eikenberg, J., Fierz T., van Dorp, F., Bossart, P., Pearson, F. J., Waber, H. N., Dewonck, S., Frutschi, M., Chaudagne, G. \& Kiczka, M. (2013). DR (Diffusion \& Retention) Experiment. Mont Terri Technical Report, TR 11-01, 49 pp. Federal Office of Topography (swisstopo), Wabern, Switzerland. http://www.mont-terri.ch.

Mazurek, M., Alt-Epping, P., Bath, A., Gimmi, T., Waber, H. N., Buschaert, S., et al. (2011). Natural tracer profiles across argillaceous formations. Applied Geochemistry, 26, 1035-1064.

Melkior, T., Yahiaoui, S., Motellier, S., Thoby, D., \& Tevissen, E. (2005). Cesium Sorption and Diffusion in Bure Mudrock Samples. Applied Clay Science, 29, 172-186.

Nagra (2014). SGT Etappe 2: Vorschlag weiter zu untersuchender geologischer Standortgebiete mit zugehörigen Standortarealen für die Oberflächenanlage: Geologische Grundlagen Dossier VI Barriereneigenschaften der Wirt- und Rahmengesteine. Nagra Technischer Bericht, NTB 14-02 (Dossier VI), 190 pp. Nagra, Wettingen, Switzerland. http://www.nagra.ch.

Naves, A., Dewonck, S. \& Samper J. (2010). In situ diffusion experiments: effect of water sampling on tracer concentrations and parameters. Physics and Chemistry of the Earth, 35, 242-247.

Palut, J. M., Montarnal, P., Gautschi, A., Tevissen, E., \& Mouche, E. (2003). Characterisation of HTO diffusion properties by an in situ tracer experiment in Opalinus clay at Mont Terri. Journal of Contaminant Hydrology, 61, 203-218.
Patriarche, D., Ledoux, E., Michelot, J. L., Simon-Coincon, R., \& Savoye, S. (2004). Diffusion as the main process for mass transport in very low water content argillites: 2. Fluid flow andmass transport modelling. Water Resources Research, 40(1), W01517.

Pearson, F. J. (1999). What is the porosity of a mudrock? Geological Society, London, Special Publications, 158, 9-21.

Pearson, F. J., Arcos, D., Bath, A., Boisson, J. Y., Fernández, A. M., Gäbler, H.-E., Gaucher, E., Gautschi, A., Griffault, L., Hernán, P. \& Waber, H. N. (2003). Geochemistry of water in the Opalinus clay formation at the Mont Terri Rock Laboratory. Federal Office for Water and Geology No. 5. Federal Office of Topography (swisstopo), Wabern, Switzerland. http://www. mont-terri.ch.

Put, M. J., De Cannière, P., Moors, H. \& Fonteyne, A. (1993). Validation of performance assessment model by large scale in situ migration experiments. Proceedings of an International Symposium on Geological Disposal of Spent Fuel and High Level and Alpha Bearing Wastes 1992 (pp. 319-326). International Atomic Energy Agency, Vienna, Austria.

Rowe, R. K., Caers, C. J., \& Barone, F. (1988). Laboratory determination of diffusion and distribution coefficients of contaminants using undisturbed clayey soils. Canadian Geotechnical Journal, 25, 108-118.

Savoye, S., Michelot, J. L., Bensenouci, F., Matray, J. M. and Cabrera, J. (2008). Transfers through argillaceous rocks over large space and time scales: insights given by water stable isotopes. Physics and Chemistry of the Earth, 33, S67-S74.

Shackelford, C. D. (1991). Laboratory diffusion testing for waste disposal: A review. Journal of Contaminant Hydrology, 7, 177-217.

Soler, J.M., Leupin, O. X., Gimmi, T. \& Van Loon, L. R. (2014). The DR-A in situ diffusion experiment at Mont Terri: Effects of changing salinity on diffusion and retention properties. In Proceedings of the Materials Research Society Symposium, Volume 1665 (pp. 63-69). Cambridge University Press.

Soler, J. M., Samper, J., Yllera, A., Hernández, A., Quejido, A., Fernández, M., et al. (2008). The DI-B in situ diffusion experiment at Mont Terri: Results and modeling. Physics and Chemistry of the Earth, 33, S196-S207.

Soler, J. M., Wersin, P., \& Leupin, O. X. (2013). Modeling of Cs ${ }^{+}$ diffusion and retention in the DI-A2 experiment (Mont Terri). Uncertainties in sorption and diffusion parameters. Applied Geochemistry, 33, 191-198.

Tachi, Y., \& Yotsuji, K. (2014). Diffusion and sorption of $\mathrm{Cs}^{+}, \mathrm{Na}^{+}$, $\mathrm{I}^{-}$and $\mathrm{HTO}$ in compacted sodium montmorillonite as a function of porewater salinity: Integrated sorption and diffusion model. Geochimica et Cosmochimica Acta, 132, 75-93.

Tachi, Y., Yotsuji, K., Seida, Y., \& Yui, M. (2011). Diffusion and sorption of $\mathrm{Cs}^{+}, \mathrm{I}^{-}$and HTO in samples of the argillaceous Wakkanai Formation from the Horonobe URL, Japan: Claybased modeling approach. Geochimica et Cosmochimica Acta, $75,6742-6759$.

Tevissen, E. \& Soler, J.M. (2003). In situ diffusion experiment (DI): synthesis report. Mont Terri Technical Report, TR 01-05, 56 pp. Federal Office of Topography (swisstopo), Wabern, Switzerland. http://www.mont-terri.ch.

Tevissen, E., Soler, J. M., Momtarnal, P., Gautschi, A., \& Van Loon, L. R. (2004). Comparison between in situ and laboratory diffusion studies of HTO and halides in Opalinus Clay from the Mont Terri. Radiochimica Acta, 92, 781-786.

Van Loon, L. R., Baeyens, B., \& Bradbury, M. H. (2005a). Diffusion and retention of sodium and strontium in Opalinus Clay: Comparison of sorption data from diffusion and batch sorption measurements, and geochemical calculations. Applied Geochemistry, 20, 2351-2363. 
Van Loon, L. R., Baeyens, B., \& Bradbury, M. H. (2009). The sorption behaviour of caesium on Opalinus Clay: a comparison between intact and crushed material. Applied Geochemistry, 24, 999-1004.

Van Loon, L. R., \& Eikenberg, J. (2005). A high-resolution abrasive method for determining diffusion profiles of sorbing radionuclides in dense argillaceous rocks. Applied Radiation and Isotopes, 63, 11-21.

Van Loon, L. R., \& Müller, W. (2014). A modified version of the combined in-diffusion/abrasive peeling technique for measuring diffusion of strongly sorbing radionuclides in argillaceous rocks: A test study on the diffusion of caesium in Opalinus Clay. Applied Radiation and Isotopes, 90, 197-202.

Van Loon, L. R., Müller, W., \& Iijima, K. (2005b). Activation energies of the self-diffusion of HTO, ${ }^{22} \mathrm{Na}^{+}$and ${ }^{36} \mathrm{Cl}^{-}$in a highly compacted argillaceous rock (Opalinus Clay). Applied Geochemistry, 20, 961-972.

Van Loon, L. R. \& Soler, J. M. (2003). Diffusion of HTO, ${ }^{36} \mathrm{Cl}^{-}$, ${ }^{125} \mathrm{I}^{-}$and ${ }^{22} \mathrm{Na}^{+}$in Opalinus Clay: Effect of Confining Pressure, Sample Orientation, Sample Depth and Temperature. Nagra Technical Report, 03-07, 145 pp. Nagra, Wettingen, Switzerland. http://www.nagra.ch.

Van Loon, L. R., Soler, J. M., \& Bradbury, M. H. (2003). Diffusion of HTO, ${ }^{36} \mathrm{Cl}^{-}$and ${ }^{125} \mathrm{I}^{-}$in Opalinus Clay samples from Mont Terri. Effect of confining pressure. Journal of Contaminant Hydrology, 61, 73-83.

Van Loon, L. R., Soler, J. M., Müller, W., \& Bradbury, M. H. (2004a). Anisotropic diffusion in layered argillaceous rocks: a case study with Opalinus Clay. Environmental Science and Technology, 38, 5721-5728.

Van Loon, L. R., Wersin, P., Soler, J. M., Eikenberg, J., Gimmi, T., Hernan, P., et al. (2004b). In-situ diffusion of HTO, ${ }^{22} \mathrm{Na}^{+}-, \mathrm{Cs}^{+}$ and $\mathrm{I}^{-}$in Opalinus Clay at the Mont Terri Underground Rock Laboratory. Radiochimica Acta, 92, 757-763.

Wersin, P., Appelo, C. A. J., Baeyens, B., Bossart, P., Dewonck, S., Eikenberg, J., Fierz, T., Fisch, H. R., Gimmi, T., Grolimund, D.,
Leupin, O. X., Möri, A., Soler, J. M., Van Dorp, F. \& Van Loon, L. (2010). Long-Term Diffusion (DI-A) Experiment: DI-A2: Diffusion of $\mathrm{HTO}, \mathrm{Br}^{-}, \mathrm{I}^{-}, \mathrm{Cs}^{+},{ }^{85} \mathrm{Sr}^{2+}$ and ${ }^{60} \mathrm{Co}^{2+}$ : Field activities, Data and Model. Mont Terri Technical Report, TR 09-04, 187 pp. Federal Office of Topography (swisstopo), Wabern, Switzerland. http://www.mont-terri.ch.

Wersin, P., Baeyens, B., Bossart, P., Cartalade, A., Dewonck, S., Eikenberg, J., Fierz, T., Fisch, H. R., Gimmi, T., Grolimund, D., Hernán, P., Möri, A., Savoye, S., Soler, J., van Dorp, F. \& Van Loon, L. (2006). Long-Term Diffusion Experiment (DI-A): Diffusion of HTO, $\mathrm{I}^{-},{ }^{22} \mathrm{Na}^{+}$and $\mathrm{Cs}^{+}$: Field activities, data and models. Mont Terri Technical Report, TR 03-06, 195 pp. Federal Office of Topography (swisstopo), Wabern, Switzerland. http:// www.mont-terri.ch.

Wersin, P., Mazurek, M., Waber, H.N., Mäder, U.K., Gimmi, T., Rufer, D. \& De Haller, A. (2013). Rock and porewater characterisation on drillcores from the Schlattingen borehole. Nagra Arbeitsbericht, NAB 12-54, 343 pp. Nagra, Wettingen, Switzerland. http://www.nagra.ch.

Wersin, P., Soler, J. M., Van Loon, L., Eikenberg, J., Baeyens, B., Grolimund, D., Gimmi, T. \& Dewonck, S. (2008). Diffusion of HTO, $\mathrm{Br}^{-}, \mathrm{I}^{-}, \mathrm{Cs}^{+},{ }^{85} \mathrm{Sr}^{2+}$ and ${ }^{60} \mathrm{Co}^{2+}$ in a clay formation: results and modelling from an in situ experiment in Opalinus Clay. Applied Geochemistry, 23, 678-691.

Wersin, P., Van Loon, L. R., Soler, J. M., Yllera, A., Eikenberg, J., Gimmi, Th, Hernán, P. \& Boisson, J.-Y. (2004). Long-term diffusion experiment at Mont Terri: First results from field and laboratory data. Applied Clay Science, 26, 123-135.

Yllera, A., Hernández, A., Mingarro, M., Quejido, A., Sedano, L. A., Soler, J. M., Samper, J., Molinero, J., Barcala, J. M., Martín, P. L., Fernández, M., Wersin, P., Rivas, P. \& Hernán, P. (2004). DI-B experiment: Planning, design and performance of an in situ diffusion experiment in the Opalinus Clay Formation. Applied Clay Science, 26, 181-196. 